\title{
Sistema radicular de porta-enxertos micropropagados de macieira colonizados com fungos micorrízicos arbusculares ${ }^{(1)}$
}

\author{
Lucir Maria Locatelli(2), Cláudio Assis Vitovski(2) e Paulo Emílio Lovato(2)
}

\begin{abstract}
Resumo - A arquitetura do sistema radicular tem implicações na capacidade da planta de obter nutrientes e água do solo; aspecto, este, não muito considerado nos estudos de desenvolvimento vegetal. O objetivo deste trabalho foi avaliar o comportamento do sistema radicular de dois porta-enxertos micropropagados de macieira (Malus spp.), em razão da associação micorrízica. Foram utilizados um porta-enxerto vigoroso e com grande capacidade de enraizamento (Marubakaido) e outro ananicante e com sistema radicular pouco desenvolvido (M.9). As plantas oriundas de micropropagação foram transferidas para substrato à base de solo, a fim de serem enraizadas ex vitro. Antes ou após o enraizamento, inoculou-se uma mistura de três isolados de fungos micorrízicos arbusculares ou um filtrado com a biota não-micorrízica do inoculante. Aos 51 e 81 dias, avaliaram-se o número e o comprimento de eixos radiculares e das raízes de ordem 1, 2, 3 e 4 . A inoculação micorrízica antes do enraizamento aumentou o número e o comprimento de raízes do porta-enxerto Marubakaido, porém, o porta-enxerto M.9 teve o número e o comprimento de raízes diminuído quando a inoculação micorrízica ocorreu antes da fase de enraizamento.
\end{abstract}

Termos para indexação: inoculação, micorriza vesículo-arbuscular, micropropagação, propagação vegetal.

\section{Root architecture of apple rootstocks inoculated with arbuscular mycorrhizal fungi}

\begin{abstract}
Root architecture is scarcely considered in plant physiology studies, despite its great importance to plant growth and development. In order to evaluate the behavior of the root systems of two varieties of apple (Malus spp.) rootstock when subjected to mycorrhizal association. Two apple rootstocks were tested: Marubakaido, which is vigorous and roots easily, and M.9, which is dwarfing and poorly rooted. The micropropagated plantlets were transferred to a soil-based substrate and received AMF inoculum, or its non-mycorrhizal biota, before and after a 21-day rooting and weaning period. After 51 and 81 days, the number and length of root axes and of first-, second-, third- and fourth- order roots were evaluated. AMF inoculation before weaning and rooting enhanced the number and length of roots in the Marubakaido rootstock. On the other hand, M.9 rootstock plantlets had their root number and length reduced when mycorrhizal inoculation was performed before the rooting period, as compared to plants receiving the AMF inoculum after the rooting period.
\end{abstract}

Index terms: inoculation methods, vesicular arbuscular mycorrhizae, micropropagation, plant propagation.

\section{Introdução}

O crescimento e o desenvolvimento vegetal dependem da estreita relação de interdependência entre a parte aérea e as raízes, as quais dão estabilidade

\footnotetext{
(1) Aceito para publicação em 19 de dezembro de 2001 .

Extraído da dissertação de mestrado apresentada pela primeira autora à Universidade Federal de Santa Catarina (UFSC), Florianópolis, SC. Financiado pela Capes, CNPq e Finep.

(2) UFSC, Centro de Ciências Agrárias, Caixa Postal 476, CEP 88040-970 Florianópolis, SC. E-mail: lucir@mbox1.ufsc.br, vitovski@matrix.com.br, plovato@mbox1.ufsc.br
}

para a planta, absorvem água e nutrientes, são o órgão onde ocorre a associação micorrízica e, em alguns casos, a fixação biológica do N (Fitter et al., 1991). A forma como as raízes se distribuem, ou seja, o padrão de suas ramificações, é a principal característica, e representa papel central na funcionalidade do sistema radicular, pois, determina sua eficiência em obter água e nutrientes do solo. As plantas que produzem maior interface com o solo têm maior potencial de absorção, o que requer maior investimento de carbono para ela crescer e manter suas raízes (Fitter et al., 1991). O desenvolvimento do sistema radicular consiste na produção, elongação e ramificação de novas raízes (Pellerin \& Pagès, 1994). 
Em condições experimentais, o crescimento do sistema radicular é usualmente expresso em termos de comprimento ou massa totais, e os fatores que afetam o crescimento e o desenvolvimento de raízes são freqüentemente definidos pela variação nestas medidas. No entanto, tais medidas, usadas isoladamente, sem considerar a dinâmica de alocação de carbono, podem levar a interpretações errôneas sobre a distribuição das raízes e a manutenção de suas funções (Fitter et al., 1991). A massa do sistema radicular é geralmente pouco correlacionada com a capacidade de absorção de nutrientes e água, porque o eixo principal, que contribui de forma preponderante para a biomassa, atua de forma restrita na absorção. Por essa razão, é importante caracterizar a arquitetura radicular das plantas, visto que são as raízes laterais que desempenham o papel principal na absorção dos nutrientes, embora contribuam pouco para a medida da biomassa (Hetrick, 1991). Apesar disso, pouca atenção tem sido dada a aspectos relacionados à arquitetura radicular, como número, comprimento, e densidade de eixos radiculares e de raízes laterais (Pellerin \& Pagès, 1994).

Estudos de arquitetura do sistema radicular avaliam padrões de ramificação e usam modelos matemáticos (Bernston,1997). Segundo esse autor, eixo radicular refere-se à porção linear do sistema radicular que se conecta com o caule - geralmente denominado de ordem 0 (zero) ou eixo radicular -, e as raízes subordinadas a este são de ordem 1 , as raízes que originam-se da raiz de ordem 1 são de ordem 2 , e assim sucessivamente. O conhecimento da distribuição das raízes de diferentes ordens é importante, porque elas têm funções diferentes, variam em crescimento, longevidade e características estruturais, bem como na capacidade de absorver água e nutrientes ou de sustentar a associação micorrízica (Hooker \& Atkinson, 1992).

Uma estratégia para a planta possuir um sistema radicular eficiente na absorção de nutrientes é o estabelecimento da associação micorrízica. A formação de micorrizas pode alterar a morfologia do sistema radicular, e o padrão de alteração varia conforme a espécie hospedeira e os fungos micorrízicos arbusculares (FMA) utilizados (Yano et al., 1996). Como as modificações na morfologia do sistema radicular promovidas pelas micorrizas são uma res- posta adaptativa da planta às condições predominantes em determinado momento (Fitter et al., 1991), o conhecimento das modificações ocorridas na morfologia de raízes colonizadas por FMA pode auxiliar no entendimento dos mecanismos pelos quais a associação influencia a absorção e a ciclagem de nutrientes em sistemas naturais ou agrícolas (Hooker \& Atkinson, 1992).

A compreensão de como e por que a morfologia é alterada pela associação micorrízica pode ajudar a prever como a planta se comportará em relação à simbiose. Assim, poder-se-á saber quais procedimentos devem ser adotados para se obter uma boa aclimatização e um crescimento mais rápido. Há um grande potencial para manipular a morfologia do sistema radicular em benefício do estabelecimento e crescimento ex vitro de plantas micropropagadas, ou mesmo de plantas produzidas em outros sistemas nos quais os FMA normalmente não estão presentes (Hooker \& Atkinson, 1992). O estudo do comportamento, frente à associação micorrízica, de porta-enxertos com sistemas radiculares de vigor diferenciado poderá trazer informações úteis na implementação de duas técnicas, a micropropagação e a micorrização de plantas.

O objetivo deste trabalho foi investigar a arquitetura radicular de dois porta-enxertos de macieira um, vigoroso e com grande capacidade de enraizamento e outro, ananicante e com sistema radicular pouco desenvolvido -, na presença ou ausência da associação micorrízica.

\section{Material e Métodos}

Foram utilizados os porta-enxertos M.9 (Malus pumila (Mill)), originado da variedade Jaune de Metz ou French Paradise; e Marubakaido (Malus prunifolia (Willd. Borkh)), que tem origem japonesa (Denardi, 1985). Na produção das mudas, as bases de brotações oriundas do processo de multiplicação in vitro, tendo 4-5 pares de folhas e 3-4 cm de altura, foram imersas em solução com $5 \mu \mathrm{M}$ de ácido indolibutírico (AIB), por 20 segundos, e transferidas para o substrato de aclimatização (Pedrotti et al., 1999).

Foram realizados dois experimentos: um, sobre o porta-enxerto Marubakaido, e outro, sobre o porta-enxerto M.9. Cada experimento utilizou um arranjo fatorial $2 \times 2$, composto de dois tratamentos de inoculação (inoculação micorrízica e não-micorrízica) e duas épocas de inoculação 
(antes e após a fase de enraizamento), com 12 repetições por tratamento, em delineamento completamente casualizado.

Como inóculo micorrízico, utilizou-se uma mistura dos seguintes FMA: Scutellospora pellucida (Nicol \& Schenck) Walker \& Sanders (isolado no 02 , da coleção da UFSC), Glomus etunicatum Becker \& Gerdemann (isolado n- 06), Glomus etunicatum Becker \& Gerdemann (isolado no 08 ) e Glomus (Tulasne \& Tulasne) sp. (isolado no 35 ). Os fungos haviam sido multiplicados em vasos com Paspalum notatum Flugge var. saurae Parodi ou Tagetes erecta L. Cada muda de macieira recebeu aproximadamente um grama de inóculo micorrízico, constituído de solo contendo esporos, hifas e fragmentos de raízes das culturas dos fungos micorrízicos. A microbiota não-micorrízica do solo foi obtida por meio da suspensão, em um litro de água destilada, de $100 \mathrm{~g}$ do inoculante micorrízico. Após agitação intensa, a suspensão obtida foi filtrada em papel-filtro com abertura de $50 \mu \mathrm{m}$, adicionando-se $1 \mathrm{~mL}$ dessa suspensão a cada uma das plantas dos tratamentos denominados não-inoculados.

O substrato utilizado - uma mistura de Terra Roxa estruturada, composto termofílico e areia na proporção de 1:1:1 (v/v/v) - foi desinfestado por 10 minutos em forno de microondas (National, modelo NE 7770KK, $2450 \mathrm{Mhz}$, 1420W) e distribuído em bandejas alveoladas com células de $120 \mathrm{~cm}^{3}$ cada. As plantas foram transferidas para as bandejas e mantidas em condições simulando túnel de aclimatização, por um período de 21 dias. Nesta fase, as plantas micropropagadas foram aclimatizadas simultaneamente à formação de raízes, sob alta umidade relativa do ar (próximo a $100 \%$ ), temperatura de $21 \pm 3^{\circ} \mathrm{C}$, fotoperíodo de 16 horas e intensidade de radiação fotossinteticamente ativa de $73 \mu \mathrm{mol} \mathrm{m}{ }^{-2} \mathrm{~s}^{-1}$ na altura média das plantas. Após esse período, os experimentos foram conduzidos em câmara de crescimento, com temperatura de $21 \pm 3^{\circ} \mathrm{C}$, fotoperíodo de 16 horas com radiação fotossinteticamente ativa de $120 \mu \mathrm{mol} \mathrm{m} \mathrm{m}^{-2} \mathrm{~s}^{-1}$ na altura das plantas. Todas as plantas receberam água diariamente e, semanalmente, aplicou-se $1 \mathrm{~mL}$ de solução nutritiva de Long Ashton (Resh, 1997) com $10 \%$ da concentração original de fósforo.

Em cada um dos experimentos foram realizadas duas coletas de dados, aos 51 e 81 dias após a saída das condições in vitro, que correspondem a 30 e 60 dias, respectivamente, após o final do período de aclimatização. Em cada coleta de dados, 12 plantas de cada tratamento foram retiradas das bandejas e tiveram as raízes cuidadosamente lavadas em água corrente e secadas em papel. A seguir, foram cortadas no nível do colo e, separaram-se as raízes para avaliação da colonização micorrízica e análise do crescimento e desenvolvimento. Os resultados referentes ao crescimento das plantas e colonização micorrízica estão relatados em outro trabalho (Locatelli \& Lovato, 2002).

O número e o comprimento do sistema radicular foram avaliados pela técnica da grade quadriculada. As raízes foram cortadas e separadas em placas de Petri, conforme a ordem à qual pertenciam: eixos radiculares, ordem 1 , ordem 2 , ordem 3 e ordem 4 . Na obtenção do número de raízes de cada ordem, os segmentos foram contados individualmente, para estimar o comprimento em cada ordem, e as raízes foram espalhadas aleatoriamente no interior de placas de Petri, divididas em quadrados de $1 \mathrm{~cm}$. Em seguida, foi registrado o número de pontos de interseção $(\mathrm{N})$ entre as raízes e as linhas verticais e horizontais da placa. O comprimento do sistema radicular ( $\mathrm{R}$ ) da amostra foi calculado de acordo com a técnica de Tennant (1975) através da fórmula: $\mathrm{R}=\mathrm{N}$ x Fator de conversão.

O fator de conversão é dependente do tamanho da quadrícula utilizada e no presente trabalho, por ter sido utilizada a quadrícula de $1 \mathrm{~cm}$, o fator de conversão foi 0,7857 .

Os dados foram submetidos à análise de variância, pelo programa STATGRAPHICS, versão 7,0, e as médias comparadas pelo teste de Newman-Keuls, a 5\% de probabilidade.

\section{Resultados e Discussão}

Na primeira avaliação, aos 51 dias, a inoculação com FMA não teve efeito significativo sobre o número total e o comprimento total de raízes do porta-enxerto Marubakaido. Não se constatou uma tendência clara de efeitos sobre o número e o comprimento de eixos e raízes de ordem 1 e 3 (Tabela 1). Houve tendências das plantas micorrizadas no início do enraizamento, de sofrerem redução de $50 \%$ no número de raízes de ordem 2 .

Os efeitos da colonização micorrízica sobre o número e comprimento de raízes manifestaram-se de forma mais evidente ao final de 81 dias (Tabela 1). O número total de raízes do tratamento colonizado em estádio inicial do enraizamento foi significativamente maior (cerca de 50\%) que nos demais tratamentos. Essa diferença no número total de raízes concentrou-se nas raízes de ordem 1 e 2 , enquanto os números de eixos e de raízes de ordem 3 e 4 não apresentaram variações significativas entre os tratamentos. O comprimento total de raízes tendeu a refletir a diferença encontrada no número de raízes, mas a diferença é derivada do maior comprimento de

Pesq. agropec. bras., Brasília, v. 37, n. 9, p. 1239-1245, set. 2002 
eixos e raízes de ordem 1 , e houve tendência $(p=0,054)$ de raízes de ordem 2 de terem maior comprimento no tratamento com inoculação precoce dos FMA. A época de introdução dos FMA revelou-se, portanto, importante, no desenvolvimento radicular do porta-enxerto Marubakaido, já que as alterações estiveram ligadas ao momento de inoculação. A presença dos FMA no início do enraizamento promoveu alterações na arquitetura radicular deste porta-enxerto, que se acentuaram ao longo do período experimental. Os benefícios da inoculação no início da fase de aclimatização têm sido demonstrados para diversas espécies micropropagadas. Assim, Branzanti et al. (1992) constataram que a melhor época para a inoculação dos FMA em macieiras é o início da fase de aclimatização, quando as plantas têm apenas primórdios radiculares.

A arquitetura do sistema radicular do porta-enxerto M.9 foi afetada pela inoculação micorrízica de forma distinta do ocorrido com o Marubakaido. Plantas do M.9 colonizadas antes da fase de enraizamento tive- ram reduzidos o número e o comprimento de raízes. Na primeira avaliação, as plantas colonizadas com FMA em estádios iniciais de enraizamento apresentaram uma redução no número total de raízes, que foi significativamente menor que o das plantas que receberam a biota não-micorrízica do solo após o enraizamento (Tabela 2). Nos dois tratamentos que receberam a biota não-micorrízica do solo, o maior número de raízes concentrava-se nos eixos e raízes de ordem 1. Apenas os tratamentos que receberam o inóculo micorrízico ou a biota não-micorrízica após a fase de enraizamento apresentaram raízes de ordem 3 , e os efeitos da inoculação ocorreram em eixos radiculares e raízes de ordem 1 . O comprimento total de raízes tendeu a refletir as diferenças observadas no número de raízes. Os menores valores de comprimento total de eixos radiculares e de raízes de ordem 1 ocorreram no tratamento com micorrização antes da fase de enraizamento. Não houve efeitos significativos da inoculação micorrízica sobre o comprimento de raízes de ordem 2 , e raízes de ordem 3

Tabela 1. Número e comprimento de eixos radiculares e raízes de ordem 1, 2, 3 e 4 e total de plantas do porta-enxerto Marubakaido micropropagadas e com inoculação de fungos micorrízicos arbusculares antes ou depois da fase de enraizamento, aos 51 e 81 dias após a saída das condições in vitro ${ }^{(1)}$.

\begin{tabular}{|c|c|c|c|c|c|c|c|}
\hline \multirow[t]{2}{*}{ Micorrização } & \multirow{2}{*}{$\begin{array}{c}\text { Época de } \\
\text { inoculação }\end{array}$} & \multirow{2}{*}{$\begin{array}{c}\text { Eixos } \\
\text { radiculares }\end{array}$} & \multicolumn{4}{|c|}{ Raízes } & \multirow[t]{2}{*}{ Total } \\
\hline & & & 1 & 2 & 3 & 4 & \\
\hline & & \multicolumn{6}{|c|}{ Aos 51 dias } \\
\hline Sim & Antes & $19 \mathrm{a}$ & $311 \mathrm{a}$ & $111 \mathrm{a}$ & $0,18 \mathrm{a}$ & $0,00 \mathrm{a}$ & $440 \mathrm{a}$ \\
\hline Sim & Depois & $17 \mathrm{a}$ & $263 \mathrm{a}$ & $176 \mathrm{a}$ & $0,18 \mathrm{a}$ & $0,00 \mathrm{a}$ & $456 \mathrm{a}$ \\
\hline Não & Antes & $15 \mathrm{a}$ & $280 \mathrm{a}$ & $194 a$ & $0,80 \mathrm{a}$ & $0,00 \mathrm{a}$ & $489 a$ \\
\hline \multirow[t]{2}{*}{ Não } & Depois & $16 \mathrm{a}$ & $305 \mathrm{a}$ & $161 \mathrm{a}$ & $0,00 \mathrm{a}$ & $0,00 \mathrm{a}$ & $482 \mathrm{a}$ \\
\hline & & \multicolumn{6}{|c|}{ - } \\
\hline Sim & Antes & $87 \mathrm{a}$ & $281 \mathrm{a}$ & $49,9 a$ & $0,07 \mathrm{a}$ & $0,00 \mathrm{a}$ & $417 \mathrm{a}$ \\
\hline Sim & Depois & $82 a$ & $334 a$ & $111,4 \mathrm{a}$ & $0,04 \mathrm{a}$ & $0,00 \mathrm{a}$ & $527 \mathrm{a}$ \\
\hline Não & Antes & $85 a$ & $353 a$ & $120,0 \mathrm{a}$ & $0,24 \mathrm{a}$ & $0,00 \mathrm{a}$ & $558 \mathrm{a}$ \\
\hline \multirow[t]{2}{*}{ Não } & Depois & $99 \mathrm{a}$ & $347 \mathrm{a}$ & $98,2 \mathrm{a}$ & $0,00 \mathrm{a}$ & $0,00 \mathrm{a}$ & $544 \mathrm{a}$ \\
\hline & & \multicolumn{6}{|c|}{ Aos 81 dias } \\
\hline Sim & Antes & $21 \mathrm{a}$ & $505 a$ & $612 \mathrm{a}$ & $49 \mathrm{a}$ & $0,82 \mathrm{a}$ & $1.189 \mathrm{a}$ \\
\hline Sim & Depois & $15 \mathrm{a}$ & $311 b$ & $417 \mathrm{ab}$ & $39 a$ & $0,00 \mathrm{a}$ & $781 b$ \\
\hline Não & Antes & $13 \mathrm{a}$ & $341 \mathrm{~b}$ & $430 \mathrm{ab}$ & $42 \mathrm{a}$ & $0,58 \mathrm{a}$ & $827 \mathrm{~b}$ \\
\hline Não & Depois & $15 \mathrm{a}$ & $310 \mathrm{~b}$ & $347 \mathrm{~b}$ & $34 \mathrm{a}$ & $0,40 \mathrm{a}$ & $706 \mathrm{~b}$ \\
\hline & & \multicolumn{6}{|c|}{--10 } \\
\hline Sim & Antes & $126 \mathrm{a}$ & $645 \mathrm{a}$ & $461,9 \mathrm{a}$ & $33,25 \mathrm{a}$ & $0,46 \mathrm{a}$ & $126 \mathrm{a}$ \\
\hline Sim & Depois & $90 \mathrm{~b}$ & $464 \mathrm{ab}$ & $321,3 \mathrm{a}$ & $24,98 \mathrm{a}$ & $0,00 \mathrm{a}$ & $900 \mathrm{ab}$ \\
\hline Não & Antes & $82 b$ & $473 \mathrm{ab}$ & $376,5 \mathrm{a}$ & $33,42 \mathrm{a}$ & $0,33 \mathrm{a}$ & $965 \mathrm{ab}$ \\
\hline Não & Depois & $87 \mathrm{~b}$ & $386 b$ & $286,1 \mathrm{a}$ & $25,22 \mathrm{a}$ & $0,39 \mathrm{a}$ & $784 b$ \\
\hline
\end{tabular}

${ }^{(1)}$ Em cada coluna, médias seguidas da mesma letra não diferem entre si a 5\% de probabilidade pelo teste de Newman-Keuls. 
foram observadas somente nos tratamentos com inoculação, micorrízica ou não, após a fase de enraizamento.

Aos 81 dias, o efeito da inoculação manifestouse no número de raízes de ordem 2 e 3 (Tabela 2). As diferenças encontradas - aos 51 dias - nos números total, de eixos e de raízes de ordem 1 desapareceram na segunda avaliação, mas observaram-se menores números de raízes de ordem 2 e 3 nos tratamentos em que os inoculantes foram adicionados antes do enraizamento das plantas. O comprimento total de raízes apresentou-se menor no tratamento colonizado com FMA antes do enraizamento, e os maiores valores foram observados nas plantas que receberam apenas biota não-micorrízica do solo após o enraizamento, com valores intermediários nos tratamentos que receberam inóculo micorrízico após o enraizamento, ou biota não-micorrízica do solo antes do enraizamento. Esse comportamento ocorreu também nas raízes de ordem 1 e ordem 2 .

A redução observada no número e comprimento de raízes no porta-enxerto M.9 submetido a inoculação com FMA antes da fase de enraizamento pode ser devida ao consumo de fotossintatos pelo simbionte fúngico, em detrimento das raízes. Esses resultados estão, em parte, de acordo com trabalhos em que plantas micorrizadas apresentaram uma redução no comprimento individual de raízes e um aumento no número de eixos radiculares (Maschke et al., 1996; Yano et al., 1996). Esses autores trabalharam com mudas previamente enraizadas, e não com a presença dos FMA na fase de enraizamento, como descrito neste trabalho.

Os dados obtidos no presente trabalho mostram que, nas condições utilizadas e no período avaliado, os FMA constituíram-se em um dreno de energia para a planta, com reflexos negativos no crescimento delas, o que indica a necessidade de seleção de outros FMA para a aclimatização do porta-enxerto M.9. As diferenças entre os porta-enxertos ocorreram porque o sistema radicular das plantas é geneticamente determinado e pode ser afetado por fatores

Tabela 2. Número e comprimento de eixos radiculares e raízes de ordem 1, 2, 3 e 4 e total de plantas do porta-enxerto M.9 micropropagadas e com inoculação de fungos micorrízicos arbusculares antes ou depois da fase de enraizamento, aos 51 e 81 dias após a saída das condições in vitro ${ }^{(1)}$.

\begin{tabular}{|c|c|c|c|c|c|c|c|}
\hline \multirow[t]{2}{*}{ Micorrização } & \multirow{2}{*}{$\begin{array}{c}\text { Época de } \\
\text { inoculação }\end{array}$} & \multirow{2}{*}{$\begin{array}{c}\text { Eixos } \\
\text { radiculares }\end{array}$} & \multicolumn{4}{|c|}{ Raízes } & \multirow[t]{2}{*}{ Total } \\
\hline & & & 1 & 2 & 3 & 4 & \\
\hline & & \multicolumn{6}{|c|}{ Aos 51 dias } \\
\hline Sim & Antes & $14 \mathrm{~b}$ & $156 \mathrm{~b}$ & $52 a$ & $0,00 \mathrm{a}$ & $0,00 \mathrm{a}$ & $223 b$ \\
\hline Sim & Depois & $29 a$ & $278 \mathrm{ab}$ & $66 a$ & $0,22 \mathrm{a}$ & $0,00 \mathrm{a}$ & $374 a b$ \\
\hline Não & Antes & $25 a b$ & $270 \mathrm{ab}$ & $72 \mathrm{a}$ & $0,00 \mathrm{a}$ & $0,00 \mathrm{a}$ & $364 a b$ \\
\hline Não & Depois & $34 \mathrm{a}$ & $359 a$ & $99 a$ & $0,55 \mathrm{a}$ & $0,00 \mathrm{a}$ & $493 a$ \\
\hline & & & 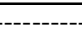 & omprim & planta $\left.^{-1}\right)$ & & \\
\hline Sim & Antes & $62 b$ & $150 \mathrm{~b}$ & $23,7 \mathrm{a}$ & $0,00 \mathrm{a}$ & $0,00 \mathrm{a}$ & $236 b$ \\
\hline Sim & Depois & $162 \mathrm{a}$ & $341 \mathrm{a}$ & $34,0 \mathrm{a}$ & $0,13 \mathrm{a}$ & $0,00 \mathrm{a}$ & $537 \mathrm{a}$ \\
\hline Não & Antes & $138 \mathrm{a}$ & $340 \mathrm{a}$ & $38,4 \mathrm{a}$ & $0,00 \mathrm{a}$ & $0,00 \mathrm{a}$ & $516 \mathrm{a}$ \\
\hline \multirow[t]{2}{*}{ Não } & Depois & $203 a$ & $495 \mathrm{a}$ & $60,2 \mathrm{a}$ & $0,21 \mathrm{a}$ & $0,00 \mathrm{a}$ & $758 \mathrm{a}$ \\
\hline & & \multicolumn{6}{|c|}{ Aos 81 dias } \\
\hline Sim & Antes & $20 \mathrm{a}$ & $376 a$ & $255 b$ & $5 b$ & $0,00 \mathrm{a}$ & $656 a$ \\
\hline Sim & Depois & $39 a$ & $464 \mathrm{a}$ & $351 \mathrm{ab}$ & $13 \mathrm{ab}$ & $0,00 \mathrm{a}$ & $868 \mathrm{a}$ \\
\hline Não & Antes & $33 a$ & $394 a$ & $287 \mathrm{ab}$ & $4 \mathrm{~b}$ & $0,00 \mathrm{a}$ & $718 \mathrm{a}$ \\
\hline Não & Depois & $26 a$ & $469 \mathrm{a}$ & $440 \mathrm{a}$ & $19 a$ & $0,00 \mathrm{a}$ & $954 \mathrm{a}$ \\
\hline & & \multicolumn{6}{|c|}{---on } \\
\hline Sim & Antes & $144 \mathrm{a}$ & $476 b$ & $182,6 \mathrm{~b}$ & $2,8 b$ & $0,00 \mathrm{a}$ & $805 b$ \\
\hline Sim & Depois & $219 \mathrm{a}$ & $613 \mathrm{ab}$ & $254,3 b$ & $8,8 \mathrm{ab}$ & $0,00 \mathrm{a}$ & $1.095 \mathrm{ab}$ \\
\hline Não & Antes & $196 \mathrm{a}$ & $575 \mathrm{ab}$ & $239,2 b$ & $2,2 b$ & $0,00 \mathrm{a}$ & $1.012 \mathrm{ab}$ \\
\hline Não & Depois & $206 a$ & $776 a$ & $388,4 \mathrm{a}$ & $13,7 \mathrm{a}$ & $0,00 \mathrm{a}$ & $1.384 \mathrm{a}$ \\
\hline
\end{tabular}

${ }^{(1)}$ Em cada coluna, médias seguidas da mesma letra não diferem entre si a 5\% de probabilidade pelo teste de Newman-Keuls. 
ambientais, como nutrição mineral, disponibilidade de água, temperatura e microrganismos do solo. Um dos efeitos mais comuns da presença da associação micorrízica é o aumento no número de ramificações das raízes, importante na ancoragem e na absorção de nutrientes e água (Berta et al., 1993).

A biota não-micorrízica do solo teve efeito sobre o crescimento e o desenvolvimento dos porta-enxertos, pois as plantas que a receberam antes do enraizamento apresentaram comportamento similar aos das plantas que receberam a inoculação micorrízica após o enraizamento. Essas observações indicam que os outros microrganismos do solo também têm efeito sobre o desenvolvimento dos porta-enxertos, e podem alterar a arquitetura do sistema radicular. Os efeitos verificados no presente trabalho no crescimento e desenvolvimento do sistema radicular dos porta-enxertos mostram a possibilidade de manipularem os FMA em combinação com outros microrganismos do solo, mas isso depende de um melhor entendimento dos sistemas produtivos e da adequada seleção de inoculantes a ser utilizado. Estudos específicos permitirão obter-se informações sobre as condições em que os FMA poderão ter sinergismo com outros microrganismos do solo (Andrade et al., 1998). Desta forma, a inoculação de FMA junto com outros microrganismos poderá assegurar o estabelecimento das micorrizas e mesmo aumentar os benefícios oriundos desta associação.

A utilização de uma mistura de FMA como inoculante não garantiu sua eficiência em todas as situações propostas no presente trabalho. Na mistura de FMA utilizada como inoculante é possível que um ou mais isolados de FMA, menos eficientes em promover o crescimento e o desenvolvimento das plantas, tenham sido mais competitivos para colonizar as raízes nas condições em que o porta-enxerto M.9 se desenvolveu.

A comparação entre os dois porta-enxertos indica que a simples presença da associação micorrízica não foi suficiente para promover alterações na arquitetura radicular, que somente ocorreram quando a inoculação micorrízica aconteceu antes da fase de enraizamento, o que sugere que a aplicação exógena de ácido indolibutírico possa ter tido efeito sobre o sistema radicular. A concentração desse hormônio nos tecidos desencadeia diferentes respostas, po- dendo determinar se o efeito será estimulador ou inibitório da ramificação. A interação entre aplicação exógena de ácido indolibutírico e a presença de FMA foi verificada em porta-enxertos de citros: plantas colonizadas com FMA e que receberam aplicação exógena de auxina apresentaram maior número de estruturas fúngicas (Dutra et al., 1996).

A presença da associação micorrízica na fase inicial do enraizamento do porta-enxerto Marubakaido mostrou-se importante e com potencial de aplicação, pelo papel que ela pode desempenhar na produção de mudas com condições de melhor estabelecimento no viveiro ou em campo, especialmente porque os efeitos de redução ou aumento do sistema radicular estiveram ligados a aumentos ou diminuições do crescimento das mudas (Locatelli \& Lovato, 2002). Contudo, para o porta-enxerto M.9 é importante estabelecer novos protocolos de inoculação, iniciando-se pela seleção de outros FMA, visto que a mistura utilizada no presente trabalho foi contraproducente em termos de promover o crescimento e desenvolvimento deste porta-enxerto. Outra possibilidade para utilização de FMA em plantas do porta-enxerto M.9 é a inoculação micorrízica tardia, em fase de viveiro.

\section{Conclusões}

1. A inoculação micorrízica promove aumento na ramificação das raízes do porta-enxerto Marubakaido.

2. A inoculação de FMA reduz o desenvolvimento do sistema radicular do porta-enxerto M.9.

3. Os efeitos, estimuladores ou inibidores, das micorrizas são mais acentuados quando a inoculação é realizada antes do enraizamento.

4. A biota não-micorrízica do solo apresenta efeitos sobre o desenvolvimento radicular de porta-enxertos de macieira, similares, mas menos acentuados, aos da associação micorrízica.

\section{Referências}

ANDRADE, G.; MIHARA, K. L.; LINDERMAN, R. G.; BETHLENFALVAY, G. J. Soil aggregation status and rhizobacteria in the mycorrhizosphere. Plant and Soil, Dordrecht, v. 202, p. 89-96, 1998.

BERNTSON, G. M. Topological scaling and plant root system architecture: development and functional hierarchies. New Phytologist, Cambridge, Inglaterra, v. 135, p. 621-634, 1997. 
BERTA, G.; FUSCONI, A.; TROTTA, A. VA mycorrhizal infection and the morphology and function of root systems. Environmental and Experimental Botany, Oxford, v. 33, n. 1, p. 159-173, 1993.

BRANZANTI, B.; GIANINAZZI-PEARSON, V.; GIANINAZZI, S. Influence of phosphate fertilization on the growth and nutrient status of micropropagated apple infected with endomycorrhizal fungi during the weaning stage. Agronomie, Paris, v. 12, p. 841-845, 1992.

DENARDI, F. Porta-enxertos. In: EMPRESA DE PESQUISA AGROPECUÁRIA DE SANTA CATARINA (Florianópolis, SC). Manual da cultura da macieira. Florianópolis, 1985. p. 92-132.

DUTRA, P. V.; ABAD, M.; ALMELA, V.; AGUSTÍ, M. Auxin interaction the vesicular-arbuscular mycorrhizal fungus Glomus intraradices Schenck Smith improves vegetative growth of two citrus rootstocks. Scientia Horticulturae, Amsterdam, v. 66, p. 77-83, 1996.

FITTER, A. H.; STICKLAND, R. S.; HARVEY, M. L.; WILSON, G. W. Architectural Analysis of Plant Root Systems. 1. Architectural correlates of exploitation efficiency. New Phytologist, Cambridge, Inglaterra, v. 118, p. 375-382, 1991.

HETRICK, B. A. D. Mycorrhizas and root architecture. Experientia, Basel, v. 47, p. 355-362, 1991.

HOOKER, J. E.; ATKINSON, D. Application of computer-aided image analysis to studies of arbuscular endomycorrhizal fungi effects on plant root system morphology and dynamics. Agronomie, Paris, v. 12, p. 821-824, 1992.

LOCATELLI, L. M.; LOVATO, P. E. Inoculação micorrízica e aclimatização de dois porta-enxertos de macieira micropropagados. Pesquisa Agropecuária Brasileira, Brasília, v. 37, n. 2, p. 177-184, fev. 2002.

MASCHKE, M.; BERTA, G.; GIANINAZZI, S.; MONCOUSIN, C. Effect of endomycorrhizal infection on root system development in the apple rootstock (Malus domestica Borkh.) M26. In: AZCÓN-AGUILAR, C.; BAREA, J. M. (Ed.). Mycorrhizas in integrated systems from genes to plant development. Granada: European Commission, 1996. p. 349-352.

PEDROTTI, E. L.; VOLTOLINI, J. A.; MACIEL, S. C. Porta-enxertos de macieira: enraizamento ex vitro e aclimatização de plantas produzidas in vitro. Revista Agropecuária Catarinense, Florianópolis, v. 12, n. 4, p. 32-34, dez. 1999.

PELLERIN, S.; PAGÈS, L. Evaluation of parameters describing the root system architecture of field grown maize plants (Zea mays L.). II. Density, length and branching of first-order lateral roots. Plant and Soil, Dordrecht, v. 164, p. 169-176, 1994.

RESH, H. M. Cultivos hidropónicos: nuevas técnicas de producción. 4. ed. Madrid: Mundi/Prensa Libros, 1997. $509 \mathrm{p}$.

TENNANT, D. A test of a modified line intersection method of measuring root length. Journal of Ecology, Oxford, v. 63, p. 995-1001, 1975.

YANO, K.; YAMAUCHI, A.; KONO, Y. Modification of root system morphology in a peanut seedling inoculated with arbuscular mycorrhizal fungus, Gigaspora margarita Becker \& Hall. Japanese Journal of Crop Science, Tokyo, v. 65, n. 2, p. 361-367, 1996. 